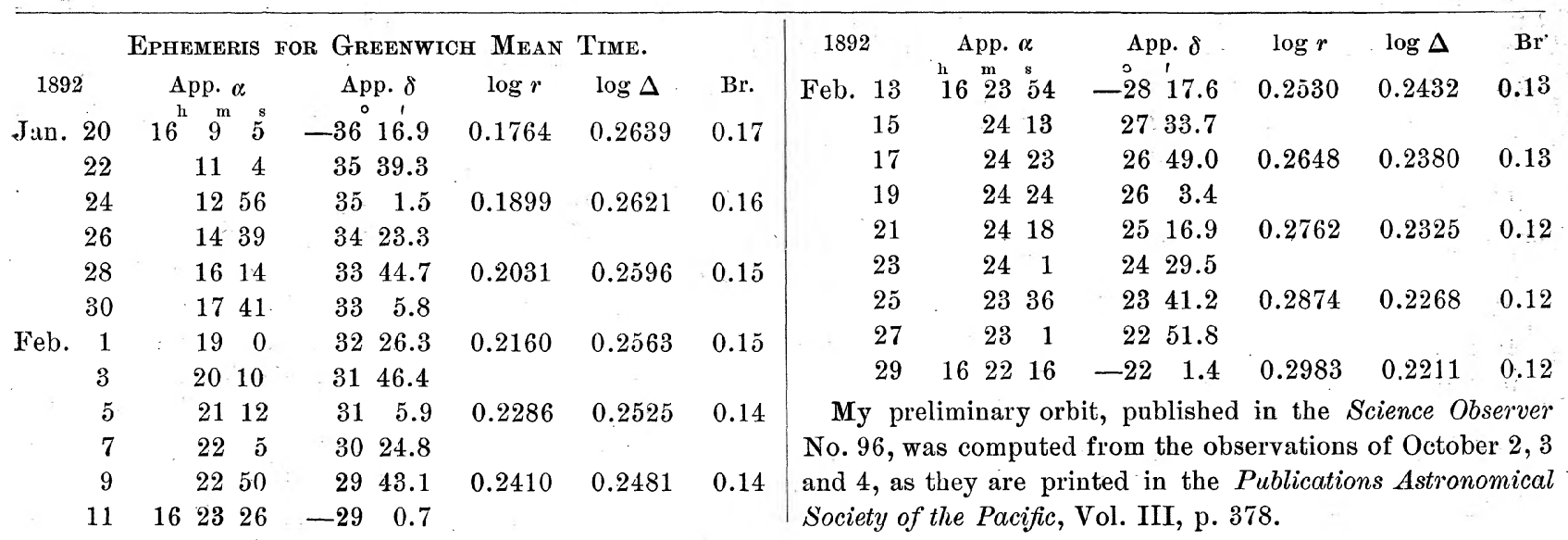

Mt. Hamilton, 1892 January 12 .

\title{
NEW ASTEROID.
}

A planet of the eleventh magnitude was discovered photographically at Heidelberg Nov. 28 . It has been observed at Vienna as follows:

1892 Jan. 20.2491 Greenw. M.T. $\quad \alpha=3^{\mathrm{h}} 50^{\mathrm{m}} 6^{8} .1, \quad \delta=+22^{\circ} 17^{\prime} 34^{\prime \prime} . \quad$ Daily motion, $+12^{\mathrm{s}}$ in $\alpha$, and $2^{\prime}$ northward.

Mr. Charlors has assigned names, as follows, to asteroids recently discovered by him :-

$$
\text { 305, Gordonia; 307, Nike. }
$$

\section{JOHN COUCH ADAMS.}

The telegraph brought tidings, on January 22, of the death of this eminent mathematician and astronomer, in his seventy-second year, after a protracted illness.

$$
\text { a...9 난 }
$$

He was born, 1819 June 5, at Laneast, a village near Lasceston, in Cornwall, England. In 1843, he graduated at Cambridge, with the highest honors, and soon afterwards undertook the investigation of the perturbations of Uranus, and of the position of the supposed disturbing planet, which soon brought him high distinction. The history of these computations, of the contemporaneous, yet very diverse, ones by LEVERRIER, and of the discovery of the disturbing body, forms one of the most curious and interesting chapters in the history of modern astronomy.

After residing in Cambridge for some years as a Fellow of St. John's College, and also serving for a short time as Professor at the University of St. Andrew's, Mr. ADAms was recalled to Cambridge in 1858, as successor to Dr. Peacock. Subsequently he became the successor of Prof. Chaldis at the Cambridge Observatory, where he has since remained.

His researches in planetary and lunar astronomy were of high value, especially those pertaining to the secular variations of the elements of the Moon's orbit. His Note on the Constant Term in the reciprocal of the Moon's Radius Vector, published in 1878, disclosed a singular property in this term, which he demonstrated with peculiar elegance.

Prof. ADAMs's astronomical activity was continued until terminated by his failing health. His latest communication to the Royal Astronomical Society was published in 1890, in The Appendix to vol. L of the Monthly Notices.

\section{CON TEN T S}

Proper Motions of 27 Southern Stars, by Prof. Lewis Boss.

On the Supposed Secular Variation of Latitudes, by Dr. S. C. Chandler.

Observations of Variable Stars at the Observatory in Upsala, by Prof. N. C. Dunér.

New Elements and Ephemeris of Comet $e$ 1891, by Mr. W. W. Campbell.

New AsteroID.

John Couch Adams. Published in Boston, Semi-monthly, By B. A. Gould, AdDress, Cambridge. Mass. Price, \$5.00 the volume. Press of Thos. P. Nichols, LyNn, Mass. 